\title{
PESSOANAMENTE: FICÇÕES ACERCA DA PESSOA DO PESSOA
}

\section{FERNANDO:}

é como eu visse-me no espelho,

mas outra pessoa.

absolutamente outra.

e mais ninguém.

\section{ALBERTO:}

mas, meu amigo,

\section{FERNANDO:}

ninguém mais.

e então surgia da sombra

uns olhos de menina.

doce. delicada.

era absurdamente delicada.

mas não era ninguém.

ninguém.

\section{ALBERTO:}

mas, meu amigo,

não existem tais aberrações;

a não ser nos olhos de quem sonha.

\section{FERNANDO:}

pois então eu estava sonhando.

mas era como se me abrisse os olhos deus.

\footnotetext{
${ }^{1}$ André Boniatti é poeta, dramaturgo, escritor, professor. Mestrando no programa Stricto Sensu em Letras, Linguagem e Sociedade, da Universidade Estadual do Oeste do Paraná/Brasil, bolsista da CAPES.
} 


\section{ALBERTO:}

deus, ah!

deus, como aquelas conversas tolas e abandonadas ao mistério.

\section{FERNANDO:}

mas era o mistério.

então, aquele ser, como se eu pudesse entender,

me falou:

\section{ALBERTO: \\ como ele era?}

\section{FERNANDO:}

"fernando, segue-me."

\section{ALBERTO:}

só isso?

\section{FERNANDO:}

não.

porque dentro de mim correram sombras e lágrimas;

lembranças doentes, mosteiros e

cavernas.

como se de mim surgisse ao mundo

um sofrimento maior

que a ruína:

de um lado, eu,

e do outro, a outra vida.

\section{ALBERTO:}

mas como ele era?

FERNANDO: 
como tu.

mas mais eu.

ALBERTO:

creio que tenha sido tudo um sonho.

FERNANDO:

não. sonho não.

ALBERTO:

e como explica o corte?

FERNANDO:

vamos voltar do princípio:

como eu disse, não acho que minha mãe fosse alheia, nem meu pai. mas eu era longe de mim.

enfurnava-me nos cantos da casa com um livro, ou um caderno, jogava palavras como uma criança, sempre,

e ia e voltava da escola sozinho.

eu cresci muito sozinho,

e achava que era deus.

ALBERTO:

deus!

FERNANDO:

mas deus eu não era,

eu era como uma poeira.

menino, eu queria ser tanta coisa... e não consegui.

o tempo foi passando e creio que eu nunca mudei. fiquei sempre o mesmo.

só criei maior medo ainda de tudo

e não sabia lidar. daí encontrei a mais linda... pessoa... 


\section{ALBERTO:}

apaixonou-se?

\section{FERNANDO:}

amei. amei não foi por moedas nem mesuras,

foi por amor.

e o rosto dela era que estava lá.

\section{ALBERTO:}

sim. mas e então?

\section{FERNANDO:}

naquela noite, quando eram sete da noite, ouviu-se um tiro no quarto.

parecia ecoar o estouro por todo lado.

vinha de fora, de longe. não era comigo.

nada comigo.

mas eu me assombrantei.

\section{ALBERTO:}

assombrantou-se... belo isso...

\section{FERNANDO:}

me assoberbei, talvez, não sei.

o fato é que crescia em mim um temor, uma sorte maldada.

uma coisa ruim,

de penas, mas de pedra.

um soco.

\section{ALBERTO:}

também já me senti.

\section{FERNANDO:}

só que era mais que o simples sentir. 


\section{ALBERTO:}

mas e então?

\section{FERNANDO}

uma cobra andava pelo meu teto. uma cobra grande. gorda.

pelo meu teto passeando. e eu observando

mudo.

não sabia o que dizer. ou seja,

o que fazer.

perdi absolutamente o tino.

\section{ALBERTO:}

vê-se que ainda está.

\section{FERNANDO:}

não voltei a quem eu era.

não voltei.

\section{ALBERTO:}

fernando, você tem falado com...

FERNANDO:

não. mas não era só isso.

quando vi aquele demônio coloquei-me a rezar.

não. não. não era reza o que eu fazia, era

dizer palavras, muitas pa-

lavras.

\section{ALBERTO:}

não precisava rezar. era só...

FERNANDO: 
era a única coisa que me restava,

ou enlouquecia!

pois então, rezei: rezei sim! rezei teve momentos que

aos brados, embora silenciosos, dentro de mim,

sem proferir em voz alta nem um sussurro.

tinha medo de falar.

\section{ALBERTO:}

medo de quê?

FERNANDO:

de que alguém me escutasse.

de que alguém estivesse me escutando a vida toda.

eu tinha medo de tudo, naquele momento.

eu, parece que ouvia

até mesmo

deus.

pensa: deus.

eu via o seu rosto, ali, refletido no quarto.

\section{ALBERTO:}

fernando!

FERNANDO:

não, alberto,

não estou endoidecido.

não sei se a maçã do éden ou de newton me caía aos olhos!

mas tudo isso eu via quieto.

\section{ALBERTO:}

e o que mais?

FERNANDO: 
no silêncio.

no silêncio, longe, eu a via.

— não ela, quem amo.

a morte.

ALBERTO:

capuz preto, ossada inderruível...?

FERNANDO:

não, alberto. não.

era muito mais terrível.

não mostrava o seu rosto.

vinha em minha direção

muda.

muda.

emudecidamente

cautelosa.

quando à minha porta...

ALBERTO:

poe.

FERNANDO:

sim. um som...

ALBERTO:

não. digo:

poe: edgar allan poe: isso me lembra o corvo

FERNANDO:

era bem como ele mesmo. 
a mesma angústia.

agora me parece ainda mais real.

ALBERTO:

fernando: a vida não é um sonho.

FERNANDO:

é, alberto. ou talvez não. ou, quem sabe...

será que estou ficando louco?

ALBERTO:

é bem possível.

o problema não é a coerência da tua fala, mas da tua vida.

a tua vida vivida, ela é que se conturba.

tua fala é bela. mas tua vida

não é sonho.

não é.

FERNANDO:

é.

ALBERTO:

e por que acha isso?

FERNANDO:

porque... acho que a prefiro assim.

a vida como sonho.

ALBERTO:

para ti, não se torna um pesadelo? 


\section{FERNANDO:}

torna-se. é.

\section{ALBERTO:}

fernando, vamos embora da cidade.

\section{FERNANDO:}

não sei se saberia me afastar da minha loucura.

não é melhor ser aquilo que não se sabe

que ser aquilo que eu sou?

aliás, o quê, quem eu sou? o que eu sou? eu não sei nem como sou.

não entendo nada de mim.

eu tenho medo e, ao mesmo tempo, amor por mim.

eu tenho medo e amor por mim, a um tempo só.

não sei se avanço ou se fico.

não sei.

\section{ALBERTO:}

pois não passe a lugar algum.

apenas deixe-se parar, fernando.

\section{FERNANDO:}

eu não consigo.

\section{ALBERTO:}

venha para o campo.

venha para lá.

vamos descansar a cabeça.

\section{FERNANDO:}

não consigo acreditar no que você acredita, alberto!

tu és doido! 


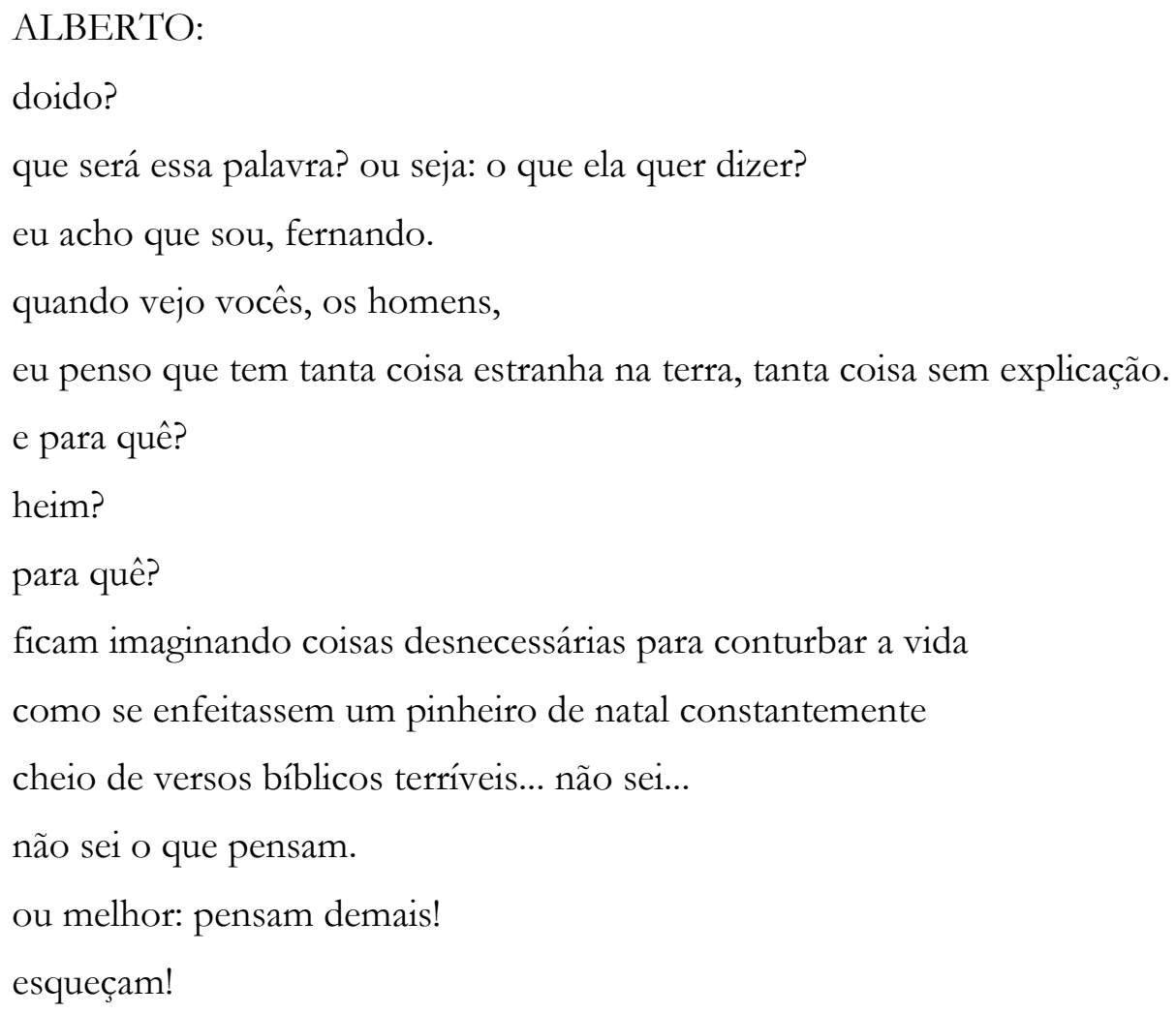

\section{ALBERTO:}

não é.

mas as coisas para mim são mais simples.

são só realidade.

\section{FERNANDO:}

ora, alberto!

\section{ALBERTO:}

pra que tem que se assombrar com redemoinhos ocultos? 
tudo está aqui, fernando. é só querer aceitar.

não tem sofrimento, é real.

não tem nem sequer lembrança.

deixe-se.

FERNANDO:

talvez. e então não haveria eu.

\section{ALBERTO:}

é claro que não.

não haveria. nem eu, nem o outro.

senão tudo. e nada.

FERNANDO:

é verdade.

\section{ALBERTO:}

é.

FERNANDO:

mas... nem existência.

\section{ALBERTO:}

depende. o que você crê que seja a existência?

pois é. talvez, só aquilo que você creia,

mais nada.

mas que importância tem você para o mundo? para o universo? para...

sei lá.

FERNANDO: 
eu disse: tu és um doido, alberto.

\section{ALBERTO:}

doido!

...sim! "Minha loucura, outros que me a tomem

Com o que nela ia. Sem a loucura que é o homem

Mais que a besta sadia,

Cadáver adiado que procria?”

é. se assim é. talvez.

mas... por que a ferida?

\section{FERNANDO:}

sim, a ferida.

como que, naquela noite, alguém parasse à frente da minha porta.

frio. muito frio. batesse

e eu tivesse, por fim, que atender.

mas não era ninguém.

\section{ALBERTO:}

não houve briga, não houve nada?

FERNANDO:

não.

\section{ALBERTO:}

bem, está congênito agora.

\section{FERNANDO:}

sim. se for esta a congenitura...

se for este o final. 


\author{
ALBERTO: \\ é verdade. \\ é verdade. \\ a congenitura. \\ o final.
}

saber que você não existe.

\title{
FERNANDO:
}

sim. saber que tu não te sabes.

\section{ALBERTO:}

mas... que você não existe...?

quão duro horror isso: saber que você não existe.

\section{FERNANDO:}

então... depois, eu, alarmado, peguei a faca.

pensei que deveria haver alguém ali. deveria haver.

um bandido sujo.

um ladrão.

não sei o que pretendia esse ser.

gritei: “apareça!

o que quer?"

nada.

e então era o rosto dela. ela. a pessoa

mais delicada. a pessoa perfeita.

não sei se imagem ou deslumbre.

lá na sombra. e não

vinha aqui.

olhei ao redor, todo lado. não havia mais nada. nada mais.

ergui a faca em direção ao peito e

cravei no estômago,

no estômago. por isso a ferida. 
queria cortar-me o prazer e o desprazer.

e foi assim. foi isso que aconteceu

naquela noite, alberto.

foi assim. 